Nevşehir Bilim ve Teknoloji Dergisi (2019), 8(Enar Özel Sayı) 64-78

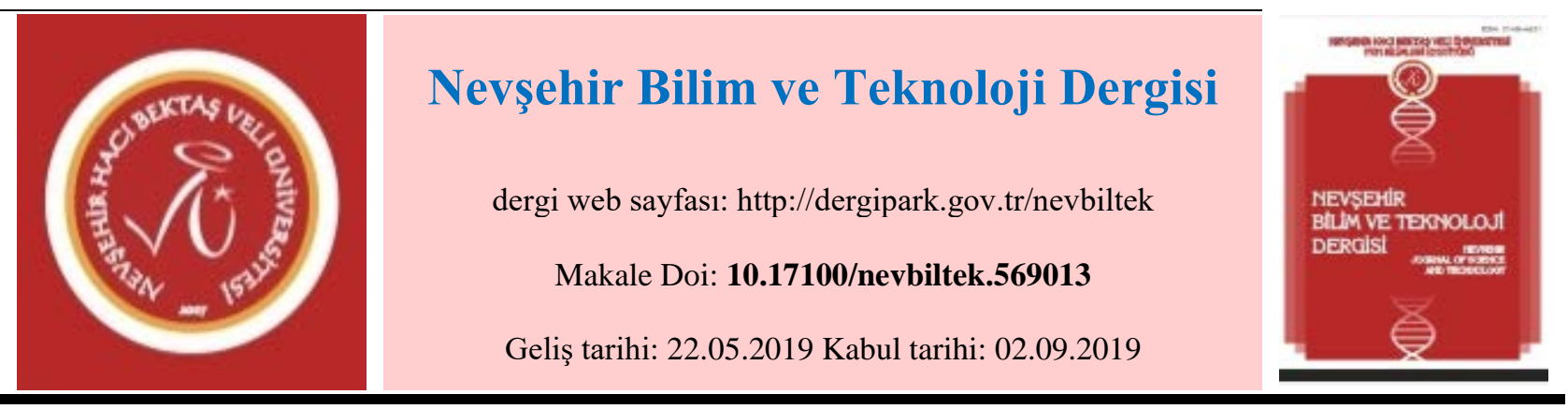

\title{
Soğuk İklim Bölgeleri İçin Yeni Bir Açık-Yeşil Alan Anlayışı; Yıl Boyu Peyzaj/Peyzaj 121
}

\author{
Hasan YILMAZ1, Naiyer GHESHLAGH SOFLA², Ayşegül AKSU³ \\ ${ }^{1}$ Atatürk Üniversitesi, Mimarlık ve Tasarım Fakültesi, Peyzaj Mimarlığı Bölümü, Erzurum/Türkiye \\ ORCID ID: 0000-0003-3768-4760 \\ ${ }^{2}$ Atatürk Üniversitesi, Mimarlık ve Tasarım Fakültesi, Mimarlık Bölümü, Erzurum/Türkiye \\ ORCID ID: 0000-0002-4508-6317 \\ ${ }^{3}$ Atatürk Üniversitesi, Mimarlık ve Tasarım Fakültesi, Peyzaj Mimarlı̆̆ı Bölümü, Erzurum/Türkiye \\ ORCID ID: 0000-0002-6720-0256
}

Öz

Artan kentleşme hareketlerine bağlı olarak kentlerde açık-yeşil alanlarınn önemi işlevsel, ekolojik, estetik, ekonomik, sosyo-kültürel açıdan giderek artmaktadır. Son zamanlarda ortaya çıkan millet bahçesi uygulamaları kentsel açık-yeşil alanların artırılması açısından oldukça yararlı görülmektedir. Bununla beraber kentlerin doğal ve kültürel kaynak değerleri ile barışık ve bütün yıl boyu kullanıma açık, özgün kentsel tasarımlara ihtiyaç vardır. Erzurum kenti özellikle yüksek rakımla beraber ortaya çıkan extrem ikli şartları nedeni ile diğer kentlerimizden ayrıcalık göstermektedir. Bundan dolayı dış mekanlarda gerek yapısal gerekse bitkisel tasarım ve uygulamalarda klasik anlayışın dışında yeni yaklaşımlara ihtiyaç duyulmaktadır. Kentte mevcut açık-yeşil alanların esnek ve dönüştürülebilir olarak bütün yıl boyu kullanımına yönelik uygulamalar yeterli değildir. Bu nedenle Erzurum gibi extrem iklim şartlarına sahip kentlerimizde kolay erişilebilen, ucuz, yıl boyu kullanılbilen, konforlu, güvenli, aktif ve pasif rekreasyon firsatlar sunan kamusal dış mekanlar yeni bir anlayışla ele alınmlıdır. Bu çalışmada dünyadaki az sayıda örnekleri bulunan dönüştürülebilen kapalı peyzaj alanları değerlendirilerek, bölgemize ve ülkemize bir model oluşturması hedeflenen Erzurum için yeni bir konsept olarak ilk kez kapalı peyzaj kavramı üzerinde durulmuştur. Çalışma sonucunda bu amaca yönelik mimari bir model oluşturulmuştur. Kentte marka değeri kazandıracak ve kent insanına tüm yıl boyunca rekreasyonel firsatlar sunması hedeflenen komplekste açık-yeşil alanlar, buz müzesi, mini arberatum (bitki müzesi), yöresel el sanatları müzesi, gastronomi vb. ünitelerle desteklenecektir. Peyzaj 12 kavramı olarak ilk kez tanımlanan kompleks ile açı-yeşil alanların yıl boyu kullanılması hedeflenmektedir. Ülkemizdeki kapalı peyzaj uygulamasının ilk örneğini oluşturacak bu özgün yapı, sadece kent halkının rekreasyonel taleplerini karşılamakla kalmayıp, aynı zamanda kentin turizminin de çeşitlendirilmesine katkı sağlayacaktır.

Anahtar Kelimeler: Kapalı mekan peyzajı, Yıl boyu peyzaj, Erzurum, Yeni açık-yeşil alan yaklaşımı

\section{A New Open-Green Concept for Cold Climate Regions; Year-Round Landscape / Landscape} 12

\section{Abstract}

Due to increasing urbanization, the importance of open-green areas in cities is increasing in functional, ecological, aesthetic, economic and sociocultural terms. In recent times, the emergence of public garden applications is seen to be very useful in terms of increasing urban open-green areas. However, there is a need for unique urban designs that are in tune with the natural and cultural resources of the cities and open to use all year round. The city of Erzurum is particularly privileged due to the extreme conditions that occur with high altitude. Therefore, new approaches are needed outside of the classical understanding in both structural and vegetative designs and applications. The applications of open-green areas available in the

\footnotetext{
${ }^{1}$ Bildirimizin özeti "2nd International Congress on Engineering and Architecture " kongresinde özet olarak sunulmuştur. Sorumlu yazar e-mail: hyilmaz@atauni.edu.tr
} 
city as flexible and convertible throughout the year are not sufficient. For this reason, public outdoor spaces that are easily accessible, cheap, yearround, comfortable, safe, active and passive recreation opportunities in our cities with extreme climatic conditions such as Erzurum should be handled with a new understanding. In this study, the concept of closed landscaping was emphasized for the first time as a new concept for Erzurum, which is intended to be a model for our region and our country by evaluating the transformable indoor landscapes with few examples in the world. As a result of this study, an architectural model was created for this purpose. In the complex, which will bring brand value and provide recreational opportunities to the city people, the complex will be supported by open-green areas, ice museum, mini arberatum (plant museum), local handicrafts museum and gastronomy. It is aimed to use the complex, light-green areas defined for the first time as the concept of "Landscape 12" throughout the year. This original structure, which will constitute the first example of the indoor landscape application in our country, will not only meet the recreational demands of the urban people, but will also contribute to the diversification of the city's tourism.

Keywords: Indoor landscaping, Year-round landscape, Erzurum, New open-green area approach

\section{Giriş}

Son on yılda, dünya genelinde özellikle gelişmekte olan ülkelerde kentsel alanlarda insan yoğunluğu artış göstermektedir [1]. Dünya nüfusunun yarısından fazlası kentsel alanlarda yaşamaktadır ve bu değerin 2050 yılına kadar \%66 'ya yükselmesi beklenmektedir [2;3]. Kentleşme süreci ile birlikte; kentsel alanların genişlemesi, genellikle yerel iklimdeki değişiklikler, çevresel koşulların bozulması, kentsel 1sı adası (UHI) etkisinin artması, hava ve gürültü kirliliği seviyelerinin artması, soğutma enerjisi tüketiminin artması, yaşam kalitesinin düşmesi, kentsel sürdürülebilirlik ilkelerinin ihlali gibi bir çok sorun meydana gelmektedir [4-5-6-7-8-9-10-11-12].

Yeşil alanlar ise bu sorunların giderilmesinde; çevresel, ekolojik, ekonomik, estetik ve rekreasyonel birçok fayda sağlamaktadır. Kentsel alanlarda yeşil alanların bulunması sıcak havalarda yerel sıcaklıkları düşürerek biyoklimatik konforu artırır. Kentsel 1sı adası etkisini azaltır [11-13-14-15-16-17-18-19-20]. İklimsel olayların olumsuz sonuçlarının ve enerji tüketiminin azaltılmasını sağlarlar [21-22]. Kirli havayı filtre ederek temiz hava temini sağlar [23-24]. Gürülttü seviyelerinin azaltılmasını sağlar [11-25-26-27]. Ayrıca insan sağlığı üzerinde sosyal fiziksel ve psikolojik açıdan olumlu etkiler yaratır. Araştırmalar kentsel alanlarda yaşayan insanların kırsal alanlarda yaşayan insanlara göre daha çok psikojik strese sahip olduğunu göstermektedir [28-29-30]. Bu sebeple kensel alanlarda yeşil aların artırılması büyük önem taşımaktadır. İnsanların kentsel yeşil alanların yeterli olduğu alanlarla etkileşim içinde olması bireylere stresli oldukları zamanlarda stresin azaltılmasına, dikkat restorasyonuna, yaşam kalitesinin, üretkenliğin ve verimliliğin de artırılmasına olanak sağlamaktadır [31-32-33-34-35-36-37-38]. Ayrıca yeşil alanlar bireylere rekreasyon, fiziksel aktivite ve sosyal etkileşim ortamı sağlamaktadır [39- 40-41-42-43-44].

Kentleşmenin arttığı günümüzde açık-yeşil alanların kentli için önemi giderek artmaktadır. Açık-yeşil alanların kent için önemini; sunmuş olduğu rekreasyonel firsatlar, büyüklüğü, kullanım yoğunluğu, konumu, kentle ilişkisi, yapı kitleleri ile ilişkisi, yönetimi ve güvenliği gibi konular belirlemektedir. Kent ve insan sağlı̆̆ı açısından, kentin marka değerinin oluşumunda, kent estetiği, ekolojisi ve yaşanabilirliği açısından açık yeşil alanların hayati önemi vardır. Açıkyeşil alanların kent için etkinliğinin artırılmasında doğal ve kültürel kaynak değerlerinin iyi analiz edilip, plan ve tasarımına katılımı ile sağlanabilir. Gerek yapısal gerek bitkisel uygulamalarda iklim faktörü belirleyici rol oynar. Bununla beraber büyük emek, para ve zaman harcanarak oluşturulan açık-yeşil alanlar, iklimin etkisi çoğu kez gözardı edildiğinden sadece yılın ve günün belirli zaman dilimlerinde aktif olarak kullanılabilmektedir. Özellikle Erzurum gibi soğuk iklim bölgelerinde yılın önemli bir bölümünde açık-yeşil alanlar halkın kullanımına cevap verecek yeni rekreasyonel yapı ve peyzaj uygulamaları yoğun ilgi görmektedir. Terkedilmiş sanayi tesislerinin mevcut iskelet yapısını koruyarak yeni işlevsel ve görsel uygulamalarla ortaya çıkan dönüştürülmüş peyzaj alanlarına yönelik irili ufaklı çok sayıda örnek mevcuttur.

Bu çalışmada bir maden ocağının ıslah edilerek özgün bir yapısına dönüştürülen “Eden Project”, bir uçak hangarının dönüştürülmesi ile ortaya çıkan "Tropical Islands Resort", tamamen kapalı peyzaj anlayışı ile oluşturulan "Seagaia Ocean Dome" ve olimpiyatlar için inşa edilip su parkına dönüştürülen "Happy Magic Water Cube" uygulamaları üzerinde durulmuştur. Bu örnekler değerlendirilerek, bölgemize ve ülkemize bir model oluşturması hedeflenen Erzurum için yeni bir konsept olarak kapalı peyzaj kavramı üzerinde durulmuştur

\section{Materyal ve Metot}

Çalışmada; öncelikle dünyadaki kapalı peyzaj uygulamalarına örnek teşkil edecek tasarımlar araştırılmış̧ır. Daha sonra bu tasarımlar incelenmiş ve yapılan incelemeler sonucunda Erzurum kenti için öneri bir model oluşturulmuştur. Modelin tasarım süreci planlamıştır. Ayrıca Peyzaj 12 projesinin uygulanması halinde sağlayacağı faydalar ve riskler ortaya konmuştur. 


\section{Bulgular}

Klasik açık-yeşil alan düzenlemelerine ek olarak planlama ve tasarımlara iklimi doğrudan katarak, kapalı peyzaj uygulamaları yeni bir konsept olarak gelişmeye başlamıştır. Endüstriyel binaların dönüştürülmesi ile ortaya çıkan tasarımlar rekreasyonel alan taleplerini tüm yıla yayarak karşılamaya olanak sağlamaktadır.

Çalışma kapsamında dünyadaki bazı kapalı peyzaj uygulamalarına örnek olarak; Eden Project, Tropical Islands Resort, Seagaia Okyanus Kubbesi ve Happy Magic Water Cube incelenmiştir.

\subsection{Dünya’ da önemli kapalı peyzaj uygulamaları}

\subsubsection{Eden Project}

Eden Project "Cennet Projesi” İngiltere 'de eski bir maden ocağından dönüştürülmüş büyük çaplı bir kompleksdir (Şekil 1). Tim Smit tarafından planlanmış olan projenin kompleksleri, 1996 yılında Nicholas Grimshaw tarafından tasarlanmıştır. 17 Mart 2001 tarihinde halka açılmış, Haziran ayına kadar 1 milyondan fazla insan ziyaret etmiştir. Kısa bir süre sonra Birleşik Krallık'a gezmeye gelen turistleri kendine çekmeye başlamıştır.

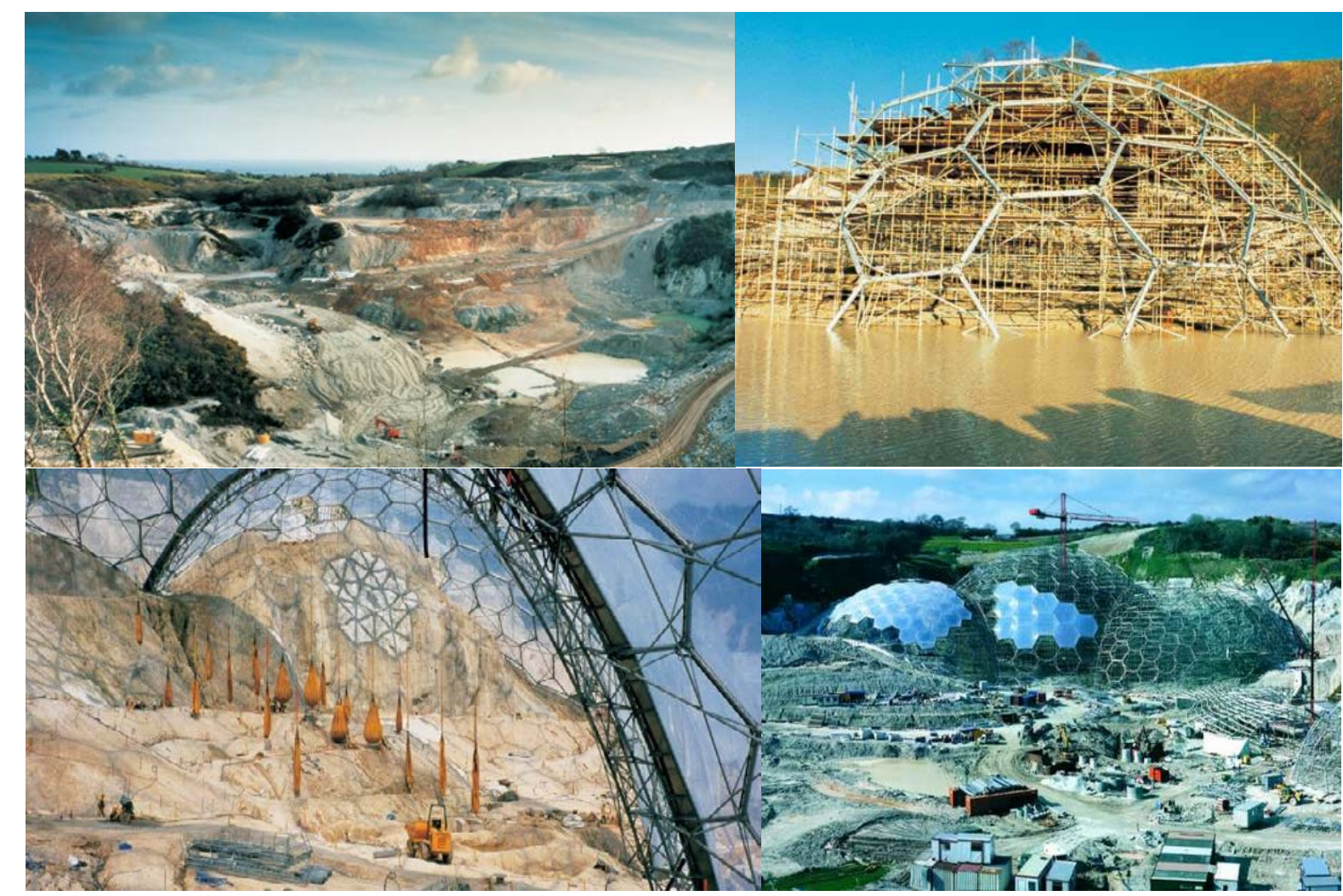

Şekil 1. Eden Project yapım aşamaları [45-46-47]

Çelik konstrüksiyonla oluşturulan dev bir böceği andıran biome 'ların kabuğu, camın kullanımı yasaklandığ için EFTE (Etilen-tetrafluoroetilen) yarı transparan bir örtü ile kaplanmıştır. Eden Project'de restorantlar, hediyelik eşya dükkanları, tropik sıcakları hissettiren yağmur ormanı biomu, Akdeniz biyomu, Batı Avusturalya bahçesi, dev heykeller, duvar resimleri, Malezya evi, sergi alanları gibi üniteler bulunmaktadır (Şekil 2). Ayrıca 3 bin 385 türe ait 97 bin 400 bitki bulunmaktadır. Eden projesi, eğitim çalışmaları, saha gezileri, konaklama, macera aktiviteleri ve düğün organizasyonları için de olanak sağlamaktadır [45-48]. 
Nevşehir Bilim ve Teknoloji Dergisi (2019), 8(Enar Özel Sayı) 64-78

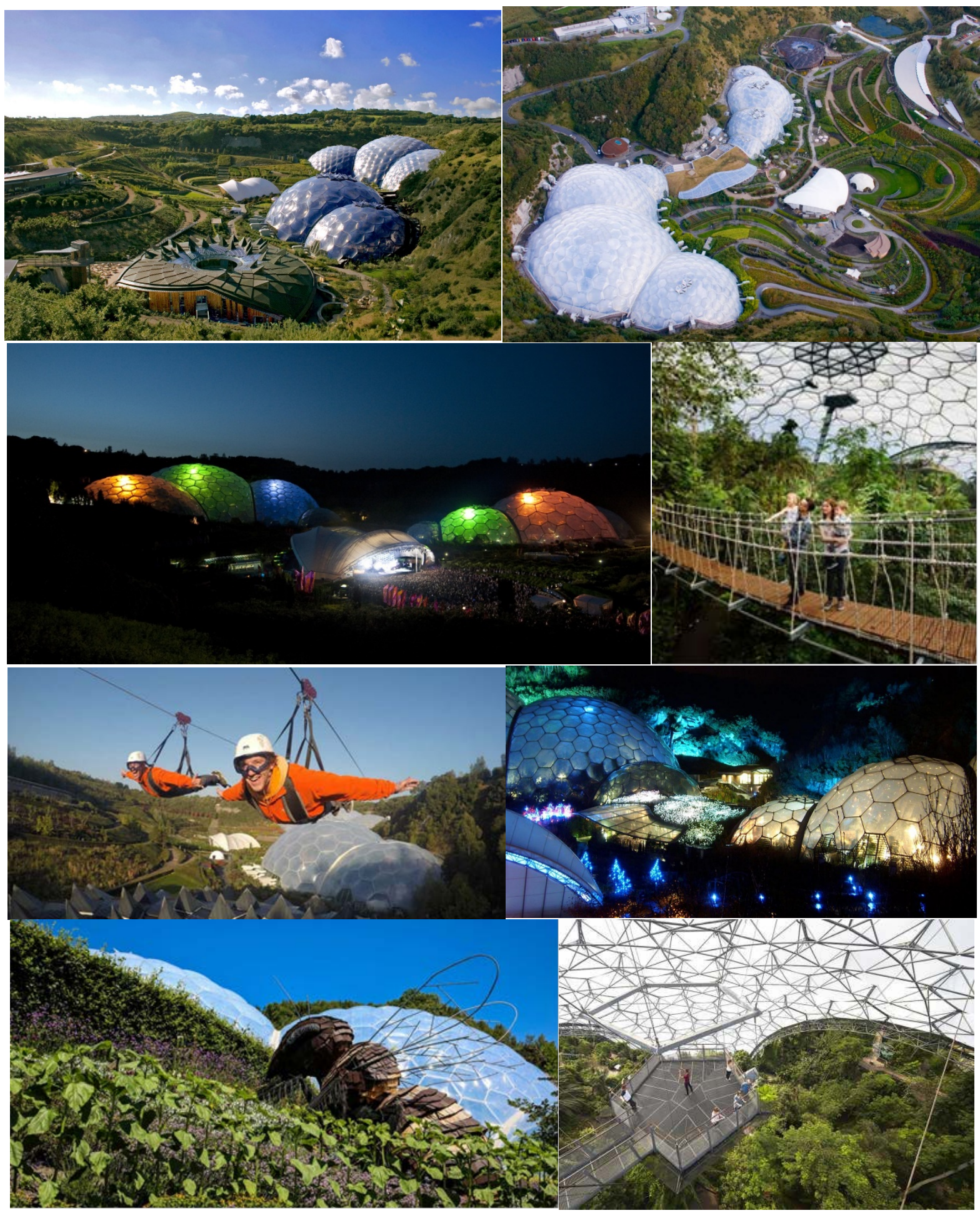

Şekil 2. Eden Project [45]

\subsubsection{Tropical Islands Resort}

Almanya'nın Brandenburg kentinde bulunan "Tropik Adalar” (Tropical Islands Resort), Malezyalı Tanjong şirketi tarafından inşa edilmiş tropik bir parktır (Şekil 3). Eskiden kargo uçağı hangarı olan mekan sadece dokuz ay içerisinde insanların gelip güzel vakit geçirebileceği ve kendilerini tropik bir adada hissedebilecekleri olanaklara sahip bir yere dönüştürülmüştür (Şekil 3). Tropik adalar 19 Aralık 2014 yılında ziyarete açılmıştır. Açıldığı yıl yaklaşık 1 milyon kişi tarafindan ziyaret edilmiş̧tir. Park günlük maksimum 6 bin ziyaretçi ağırlayabilecek kapasiteye sahiptir [4950] 
Nevşehir Bilim ve Teknoloji Dergisi (2019), 8(Enar Özel Sayı) 64-78
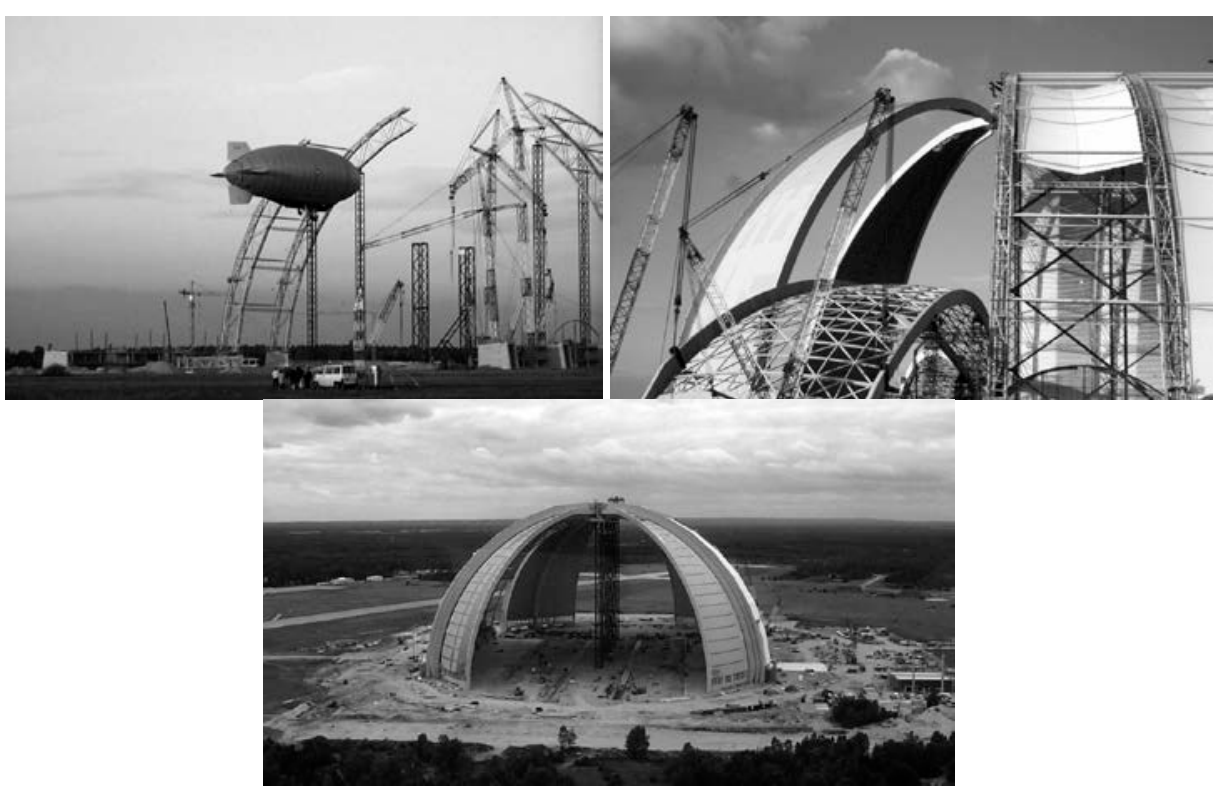

Şekil 3. Tropik Adaların yapım aşamaları [50]

Tropik Adalar $360 \mathrm{~m}$ uzunluğunda $210 \mathrm{~m}$ genişliğinde, $107 \mathrm{~m}$ yüksekliğinde ve 5,5 milyon metreküp hacme sahiptir. Mekan 2 ana bölümden oluşmaktadır. Bölümlerden birisi Tropik Sauna ve Spa Kompleksi diğeri ise Tropik Dünya'dır. Tropik Adalar'da 50.000 bitki ve 600 farklı bitki türüyle dünyanın en büyük iç mekan yağmur ormanları, plaj, tropik bitkiler, bir çok yüzme havuzu, yapay mağara jakuzi, $27 \mathrm{~m}$ yüksekliğinde su kaydırağı kulesi, $250 \mathrm{~m}$ uzunluğunda akış kanalı, golf sahası, geleneksel Tayland evi, tropikal köyün içinde gezinti yapma olanağı sağlayan İzlanda baloncuğu, Afrika orman asansörü, restoranlar, heykeller, flamingo ve kaplumbağa gibi bir çok hayvana ev sahipliği yapan bir bataklık ve çocuk kulübü bulunmaktadır(Şekil 4; Şekil 5) [49-50].
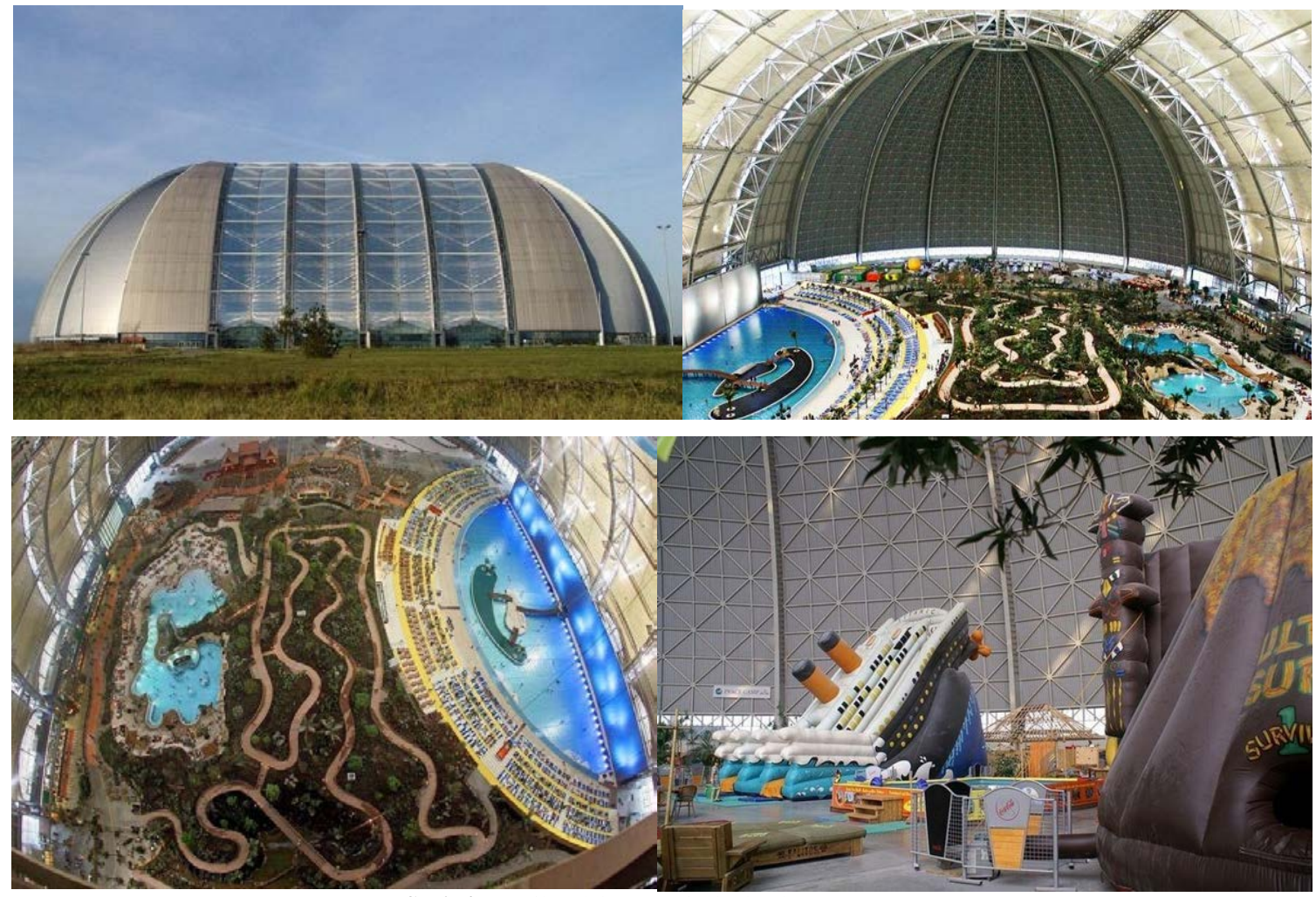

Şekil 4. Tropik Adalar (Tropical Islands Resort) [51] 
Nevşehir Bilim ve Teknoloji Dergisi (2019), 8(Enar Özel Sayı) 64-78

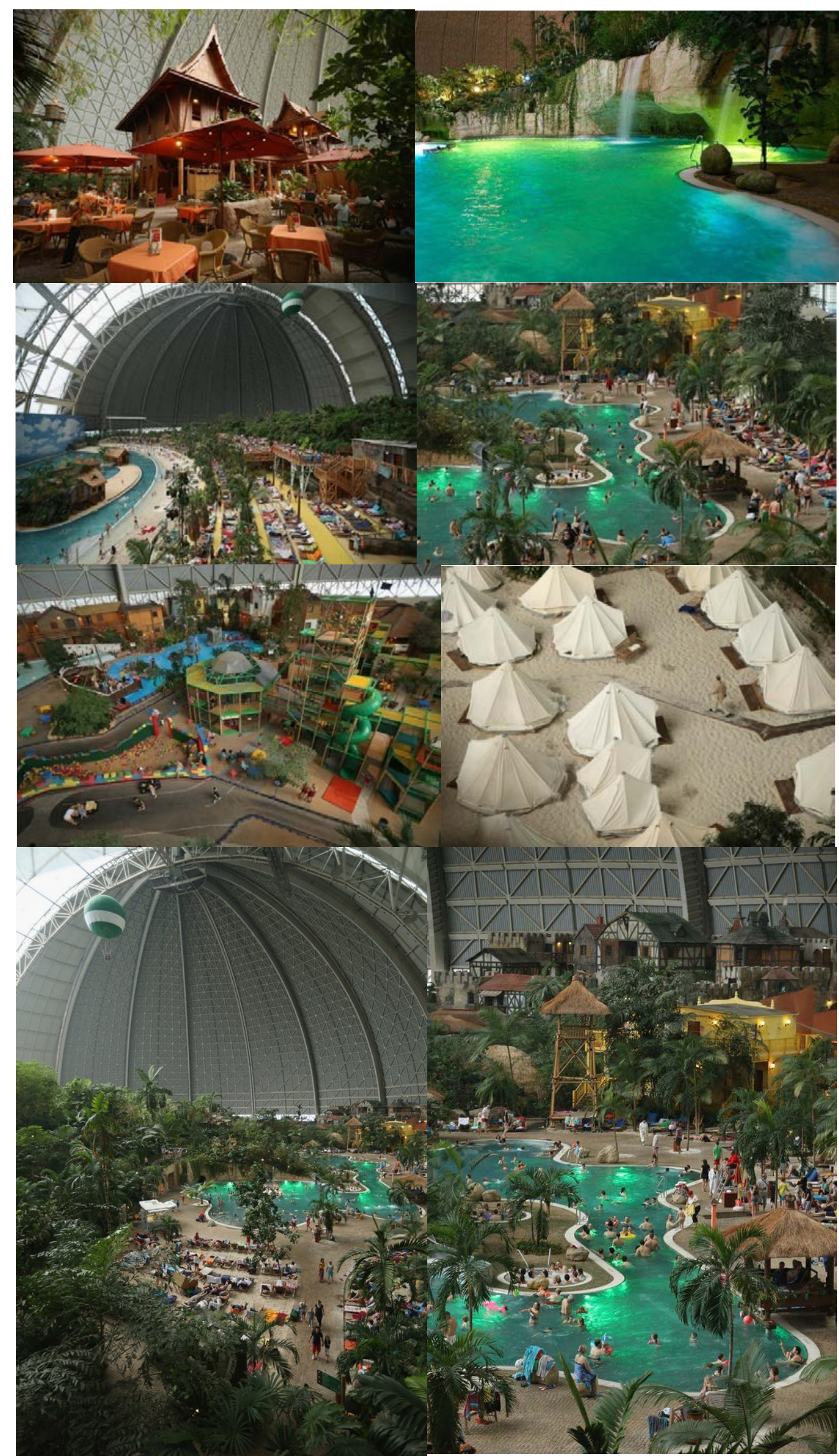

Şekil 5. Tropik Adalar (Tropical Islands Resort) [52] 


\subsubsection{Seagaia Okyanus Kubbes}

Dünya'daki en büyük kapalı su parkı olan "Seagaia Okyanus Kubbesi” (Seagaia Ocean Dome), Japonya'nın Miyazaki şehrinde bulunmaktadır (Şekil 6). 1993 yılında açılmıştır. 1995 yılında 1,25 milyon ziyaretçi sayısına ulaşmıştır. Aynı anda yaklaşık 10.000 kişiyi ağırlama kapasitesi bulunmaktadır. Kapalı bir mekan olup, istenildiğinde açılabilen metal kubbe şeklinde dünyanın en büyük geri çekilebilir çatısına sahiptir. Kubbe yüksekliği 38 m’dir. Hava sıcaklığı her zaman yaklaşık $30^{\circ} \mathrm{C}\left(86^{\circ} \mathrm{F}\right)$ ve su da yaklaşık $28^{\circ} \mathrm{C}^{\prime}$ de $\left(82^{\circ} \mathrm{F}\right)$ tutulmaktadır. Gerçek tropik ağaçlar ve palmiye ağaçları gibi birçok ağacın bulunduğu alanda gerçek maymunları da görmek mümkündür. İçerisinde birçok cazibe merkezi, restoran, kafe, sinema, plaj, kayıklar, salıncaklar ve dinlenme alanları bulunmaktadır [46-53].
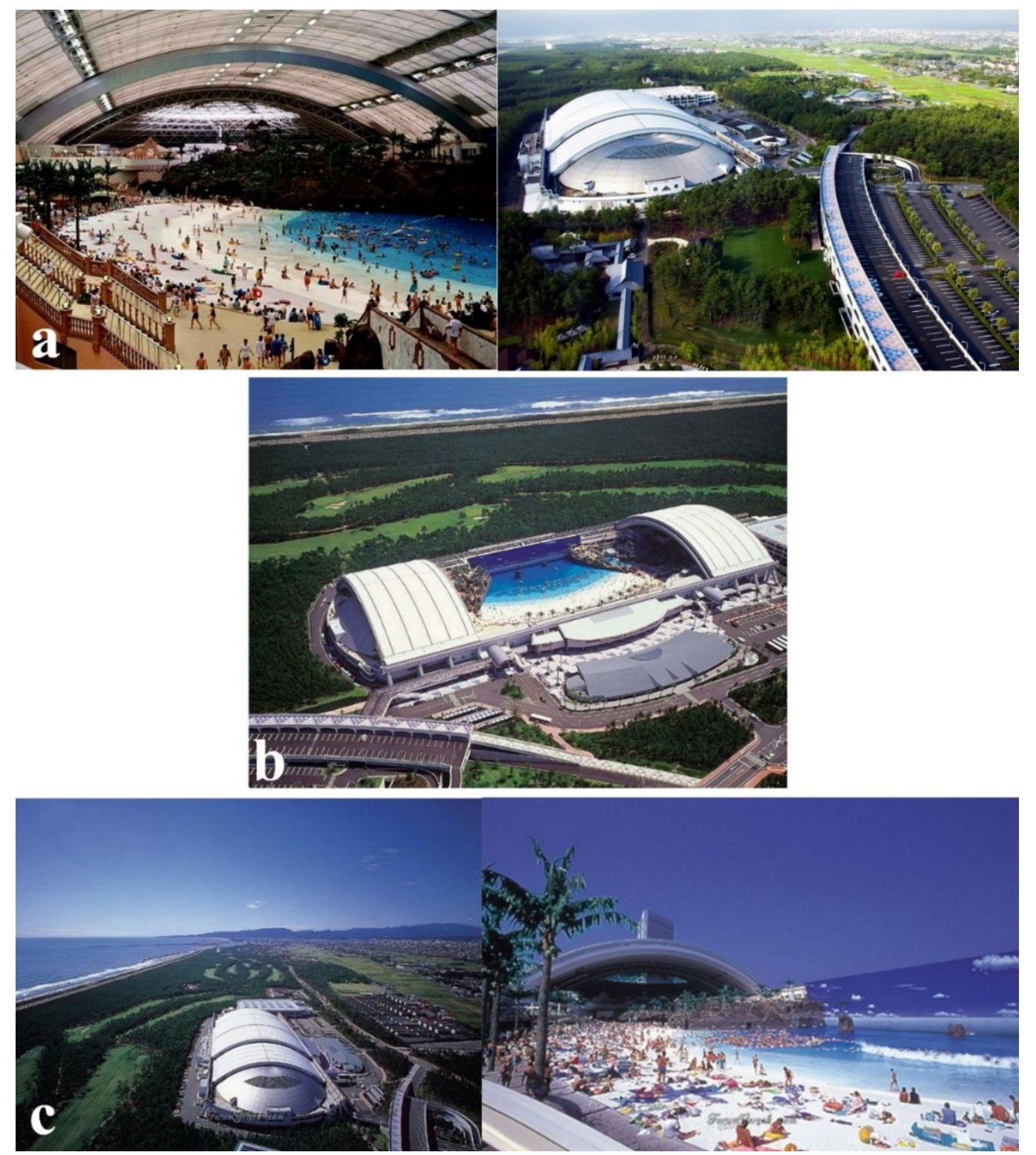

Şekil 6. Seagaia Okyanus Kubbesi (Seagaia Ocean Dome) (a- [53]; b- [54]; c- [55])

\subsubsection{Happy Magic Water Cube}

Çin ‘in Pekin şehrinde bulunan 'Sihirli Su Küp' (Happy Magic Water Cube) renkli su parklarından birisidir (Şekil 7). 2008 Olimpiyat Oyunları için özel olarak inşa edilmiştir. Etkinlikten sonra su parkına dönüştürülmüştür. Binası modern mühendisliğin en güzel örneklerindendir. Büyük bir denizanası, devasa bir su damlası ve buz kristallerini içeren tavan muhteşem sanatsal aydınlatmalarla tamamlanmıştır. Bina akşamları muhteşem bir aydınlatma ile parlamaktadır [56]. 


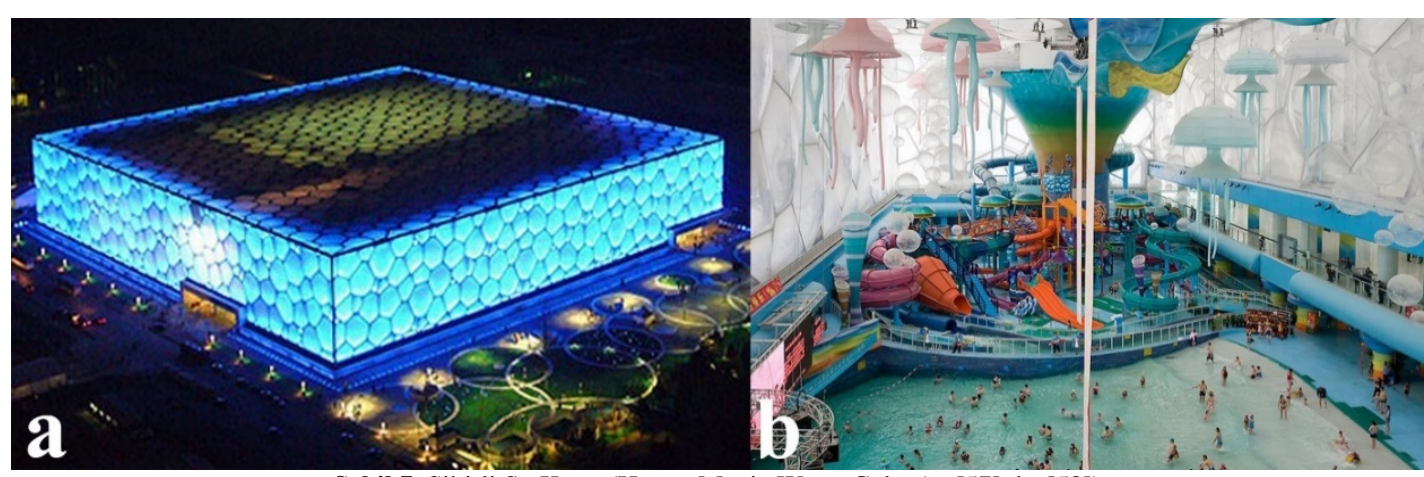

Şekil 7. Sihirli Su Küpü (Happy Magic Water Cube (a- [57]; b- [58])

\subsection{Erzurum kenti için yıl boyu peyzaj; Peyzaj 12 fikir projesi}

Birçok tarihi eseri bünyesinde barındıran Erzurum kenti, stratejik konumu, kış turizm merkezi, 2 adet üniversitesi, çok sayıda resmi kurumun bölge müdürlükleri, ulaşım, sağlık ve hizmet sektöründeki gelişmeler ile Doğu Anadolu Bölgesinin en önemli kentlerinden birisidir. Yüksek rakımın oluşturduğu ekstrem kış şartları nedeni ile ülkemizde soğuk iklimi temsil eden kentlerin başında yer almaktadır.

Büyük para, zaman ve emek harcanarak kentsel açık-yeşil alanların artırılmasına yönelik olumlu gelişmeler yaşanan kentte, özellikle uzun kış sezonu boyunca kullanılabilecek rekreasyonel alanlar birkaç alışveriş alanı dışında neredeyse bulunmamaktadır. Küçük ölçeklerde kış bahçesi, küçük kapalı teras, balkon veya alışveriş mekanlarındaki küçük ölçekli mekanlar dışında peyzaj mekanlarının yıl boyu kullanımına yönelik alanlar yok denecek kadar azdır.

Kış turizmi alanında ülke ve dünya çapında bir marka değerine sahip olan kentin turizmi bütün yıla yayma açısından alternatif yeni kaynak değerlerinin planlamasına ihtiyaç vardır. Yurtdışında bu amaçla oluşturulan kapalı peyzaj mekanları yoğun turist çekmektedir. Bu amaçla Erzurum kentinde açık-yeşil alanların yeni bir planlama anlayışı ile ele alınması gerekmektedir. Mahalle ve kent ölçeğinde oluşturulan parkların yanısıra yıl boyu kent, bölge ve yöreye gelecek ziyaretçilere hizmet edecek kapalı peyzaj uygulamaları bir zorunluluk durumuna gelmiştir.

Y1l boyu peyzaj/Peyzaj 12 kompleksine yönelik bio tasarım ürünü olarak yeni bir konsept tasarım ortaya konulmuştur. Doğadaki lif yapılarından yola çıkarak tasarrlann yapı adası açık ve kapalı donatıları içermektedir (Şekil 8).

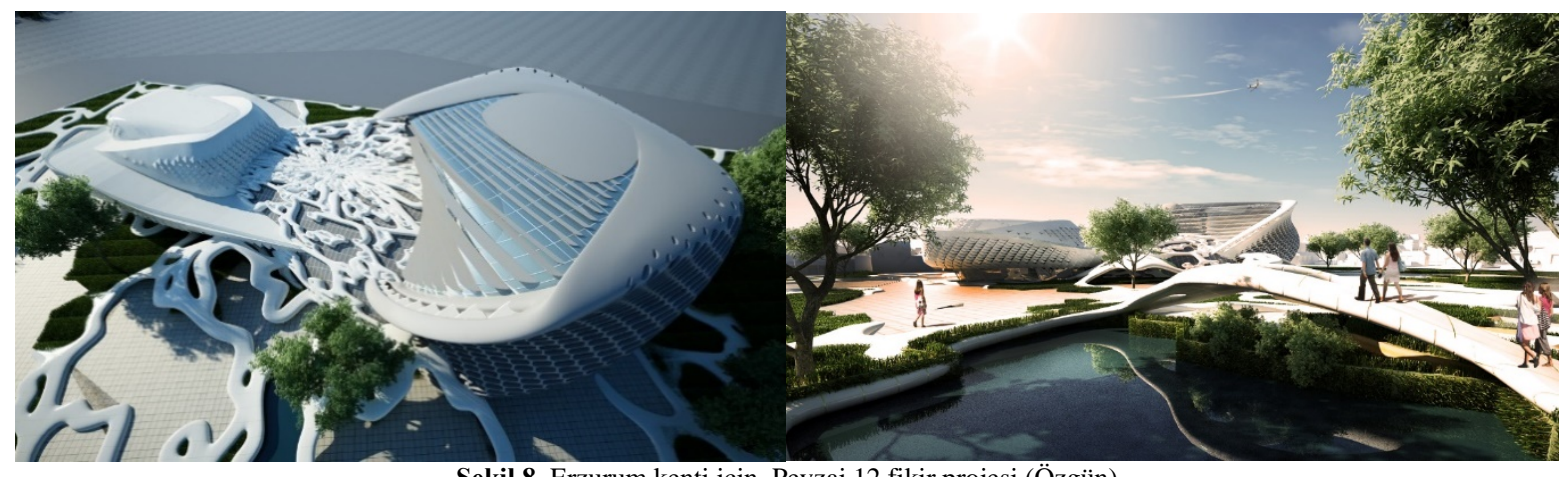

Şekil 8. Erzurum kenti için Peyzaj 12 fikir projesi (Özgün)

\subsubsection{Peyzaj 12 Projesi planlama ve tasarım süreci}

Peyzajın yıl boyu aktif olarak kullanılmasına yönelik yapılacak plan ve tasarımlar bu çalışmada Peyzaj 12 olarak tanımlanmıştır. Bu tanım veya yaklaşım ilk kez kullanılmaktadır.

Peyzaj 12, açık-yeşil alanların; her yaş, cinsiyet ve gelir seviyesindeki ziyaretçilere rekreasyonel firsatlar sunan, bulunduğu kente ekolojik, estetik, işlevsel ve ekonomik kazançlar sağlamayı hedefleyen, konforlu, erişebilir ve güvenli, iklimin olumsuz etkilerini ortadan kaldırıcı yıl boyu kullanılabilen kentsel peyzaj tasarımlarıdır.

\subsubsection{Yönetim planının oluşturulması/ Kamuoyu oluşturulması}

- Peyzaj 12 fikir projesinin İlgili Bakanlık, Atatürk Üniversitesi ve yerel yönetim ile işbirliğinin/paydaşlar protokolün oluşturulması

- $\quad$ Fayda-zarar analizlerinin yapılması 
Nevşehir Bilim ve Teknoloji Dergisi (2019), 8(Enar Özel Sayı) 64-78

- $\quad$ Erzurum Valiliği ve ilgili kamu kurumları, Kalkınma ajansı (KUDAKA), DAP ve Turizm yatırımcılarının projeye katılımının sağlanması

- $\quad$ Yerel ve ulusal basın, sivil toplum örgütleri ve halkın projeye katılımının ve ilgisinin sağlanması

\subsubsection{Peyzaj 12 proje alanının belirlenmesi}

- $\quad$ İlgili yerel yönetimle altyapı, ulaşım, konum, büyüklük, topoğrafya, iklim ve sosyo ekonomik ve kültürel yapıya en uygun alanın belirlenmesi

- $\quad$ İlgili yasal düzenlemelerin yapılması

\subsubsection{Peyzaj 12 projesinin donatılarının belirlenmesi}

- $\quad$ Ana teması kapalı açık-yeşil alan düzenlemeleri

- Mini arboretum/bitki müzesi/bitki kolleksiyonları

- $\quad$ Durgun ve hareketli su yüzeyleri

- Fuar ve sergi alanları

- Meydan, anfitiyatro, bakı terasları

- $\quad$ Müzeler (el sanatları müzesi, tarihe yön verenler müzesi, buz müzesi vb)

- $\quad$ Yöresel mutfağa hizmet veren yeme içme alanları (gastronomi)

- $\quad$ Yöresel mimari sokak

- Diş mekan düzenlemeleri ve otopark

- Diğer alan kullanımları (Proje tasarımcılarının önerileri doğrultusunda)

\subsubsection{Peyzaj 12 tasarım ve uygulama projesinin oluşturulması}

- $\quad$ Yerel ve ülkesel ölçekte konu uzmanlarından (Peyzaj mimarı, mimar, şehir plancısı, inşaat müh, makine müh, sanat tarihçisi, sosyolog, güzel sanatlar uzmanı, yerel yöneticiler, kamuyu temsilen uzmanlar, turizm uzmanı, basın mensubu, sivil yoplum yöneticileri vb).

- $\quad$ Tasarım kompleksinin ana mimari konseptinin belirlenmesi

- $\quad$ İklime kontrol eden mimari yaklaşım/akıllı bina

- $\quad$ Ulusal bir yarışma düzenlemek

- $\quad$ Yarışma sonuçlarının jüri tarafından değerlendirilmesi ve kamuoyu ile paylaşılması

\subsubsection{Proje Uygulama aşaması}

- $\quad$ Seçilen ve kamuoyu ile paylaşılan projenin uygulamaya başlanılması

- Projenin her aşamasını kontrol ve olası sorunlara müdahale eden danışmanlar kurulunun oluşturulması

- Değişik aşamaların kamuoyuna duyurulması

\subsubsection{Peyzaj 12 projesinin uygulamaya açılması/tamamlanması}

- 2023 yilında Cumhuriyetin 100. Yilında projenin hizmete girmesi

- $\quad$ Açılışın ulusal ve uluslararası geniş katılımlı yapılması

- Tanıtımın yapılmasına yönelik çalışmaların yapılması

- Yönetim planlamasının yapılması 
Nevşehir Bilim ve Teknoloji Dergisi (2019), 8(Enar Özel Sayı) 64-78

\subsubsection{Erzurum kenti için Peyzaj 12 fikir projesinin sağlayacağı yararları}

Projenin gerçekleşmesi durumunda Erzurum kentine ve kent halkına birçok yararlar sağlayacağı düşünülmektedir. Bu yararlar; ekonomik, rekreasyonel, ekolojik, kent imajına katkı olarak belirlenmiştir.

\subsubsection{Ekonomik faydalar}

- $\quad$ Yöre ekonomisine katk1

- $\quad$ Turizme doğrudan katkı (ulaşım, konaklama, gıda sektörü, alış-veriş vb.)

- $\quad$ İstihdama doğrudan katk1

- Yakınındaki taşınmaz değerlerindeki artış

- $\quad$ Yeni iş kollarının açılması

\subsubsection{Rekreasyonel faydaları}

- $\quad$ Yil boyu açık -yeşil alandan güvenli bir şekilde yararlanma

- $\quad$ Özellikle kış aylarında kent insanına alternatif dış mekan kullanımı

- $\quad$ Klasik park anlayışından uzak, özgün mekanların sunduğu rekreatif firsatlar

- $\quad$ Kentin stresli ve kasvetli havasından kurtulma

- Ruhen ve bedenen yenilenme, sosyalleşme

- $\quad$ Yeni bitki türlerini tanıma

\subsubsection{Ekolojik faydaları}

- $\quad$ Kentin diğer açık-yeşil alan sistemi ile entegrasyonu

- $\quad$ Akıllı bina yönetimi ile güneş enerjisini etkin kullanma

- Yerel mimariye örnek oluşturarak, kaynakların etkin kullanımı

- $\quad$ Çevre ve doğa bilincini artırma

- $\quad$ Kente ek açık-yeşil alan kazandırma

- $\quad$ Çevreye duyarlı, iklimi kontrol eden, ısıtma masraflarını azaltarak kapalı mekan oluşturma

\subsubsection{Kent imajına katkı sağlama}

- $\quad$ Ülkemizin ilk peyzaj 12 projesi olması nedeni ile kentin prestijine katk1

- $\quad$ Alternatif yaşam alanları oluşturma

- $\quad$ Kentin markalaşmasına doğrudan katkı

- $\quad$ Özellikle uluslararası tanınırlığa doğrudan katkı

- $\quad$ Ulusal ve uluslararası fuar, sergi ve toplantılarla kente katkı sağlama

- $\quad$ Yaşanabilir kent kavramına doğrudan katkı

- S Soğuk iklim kentleri için model oluşturma

\subsubsection{Peyzaj 12 projesinin taşıdığı riskler}

Ülkemizde ilk kez Erzurum kentinde planlanan büyük ölçekli kapalı peyzaj alanı için; plan, tasarım, uygulama ve yönetimi aşamalarında aşağıdaki riskleri mevcuttur.

- İlgili bakanlık ve yerel yönetimlerin konuya isteksiz yaklaşımları

- $\quad$ Bu konudaki deneyimlerin yetersizliği

- $\quad$ Proje maliyetinin yüksek olması 
- Kapalı mekanın iklimlendirilmesi (kışın 1sıtma, yazın havalandırma) işlemlerin zorluğu

- $\quad$ Alanın yönetimi ve sürdürülebilirliğinde karşılaşılması olası zorluklar (ısıtma ve havalandırma masrafları, yönetim ve bakım, kontrol organizasyonları vb.)

\section{Tartışma ve Sonuç}

Uzun ve sert iklim koşullarına sahip olan Erzurum kent merkezinde bulunan dış mekan açık-yeşil alanlar yıl boyunca kullanılabilecek donanıma sahip değildir. Kentte iklim koşullarına bağlı olarak kış turizmine yönelik faaliyetelere olanak sağlayacak tesisler bulunmaktadır. Ancak bu tesisler ekonomik durumu belli bir seviyenin üzerinde olan kent sakinleri tarafından kullanılmaktadır. Ülkemizdeki en önemli kış turizm merkezlerinden birisi olan Palandöken Kayak Merkezi kent sakinlerinin bir kısmının rekreasyonel taleplerini karşılamaktadır. Bu tesisler daha çok turizme yöneliktir. Kent içinde dış mekan kullanımlarına yönelik yapılan çalışmalar olumlu olmakla beraber farklı ekonomik, sosyal ve kültürel yapıya sahip olan kent sakinlerinin yıl boyu faydalanabileceği açık-yeşil alanlara ihtiyaç vardır. Kolay erişilebilen, ucuz, konforlu, güvenli, her yaş ve cinsiyetten insanların kullanabileceği kamusal dış mekanlar yeni bir anlayışla ele alınarak bu yönde çalışmalar yapılmalıdır. Erzurum kentinin özellikle bölgemizin en gelişmiş yerleşkelerinden biri olması, ana ulaşım koridoruna sahip olması, kış turizmi ile dünyaya açılması, sağlık ve eğitim merkezi durumunda olması, ekstrem iklim şartları vb gibi kaynak değerleri göz önüne alındığında yeni açık yeşil alanlar planlama ve tasarımı yapılarak uygulamaya geçilmelidir. Kış aylarında özellikle kapalı mekan peyzaj tasarımları kentte ön planda tutulmalıdır. Kentte marka değeri kazandıracak ve kent insanına tüm yıl boyunca rekreasyonel firsatlar sunacak büyük bir bölge parkı içerisinde kapalı peyzaj düzenlemelerine gidilmelidir. Yapılan kompleks buz müzesi, buz sporları, biyoçeşitlilik müzesi, mini arberatum (bitki müzesi), lokal alışveriş ve geleneksel el sanatları müzesi, gastronomi vb. ünitelerle desteklenerek rekreasyon çerçevesi genişletilmelidir. Finansman sorunların aşılması durumunda hayata geçirilecek tasarım yılın sadece belirli bir bölümünde kullanılan birçok park yerine kent, bölge ve ülkede örnek oluşturacaktır. Ayrıca bu kompleks sadece Erzurum kenti sakinlerine değil yakın illere de hizmet olanağı sağlayacaktır. Böylece Erzurum kenti için turizmi de hareketlendirecektir.

Sonuç olarak Erzurum kenti gibi ekstrem iklim koşullarına sahip olan ve soğuk kent kimliği taşıyan kentsel mekanlarda dış mekan peyzaj düzenlemelerinde var alanın aksine yeni ve farklı yaklaşımlara ihtiyaç vardır. Dış mekan kullanımınlarını bütün yıla yayma açısından kapalı peyzaj mekan düzenlemeleri ön plana çıkarılmalı ve uygulanmalıdır. $\mathrm{Bu}$ tip kompleksler kent halkının tüm yıl rekreasyon ihtiyaçlarını karşılamakla kalmaz aynı zamanda kentin marka değerlerini artırmada önemli rol oynar. Ayrıca kentte turizme katkı sağlayarak çeşitlilik sağlarlar.

\section{Kaynaklar}

[1] Turner, W. R., Nakamura, T., \& Dinetti, M. (2004). Global urbanization and the separation of humans from nature. Bioscience, 54(6), 585-590.

[2] United Nations, Department of Economic and Social Affairs, Population DivisionWorld Urbanization Prospects: The 2014 Revision, CD-ROM Edition United Nations (2014) ([Internet], [cited 2017 Jun 20]). Available from: https://esa.un.org/unpd/wup/CD-ROM/

[3] Yan, H., Wu, F., \& Dong, L. (2018). Influence of a large urban park on the local urban thermal environment. Science of The Total Environment, 622, 882-891.

[4] Bridgman, H. A., Warner, R. F., \& Dodson, J. R. (1995). Urban biophysical environments. Oxford University Press.

[5] Decker, E. H., Elliott, S., Smith, F. A., Blake, D. R., \& Rowland, F. S. (2000). Energy and material flow through the urban ecosystem. Annual Review of Energy and the Environment, 25(1), 685-740.

[6] Patz, J. A., Campbell-Lendrum, D., Holloway, T., \& Foley, J. A. (2005). Impact of regional climate change on human health. Nature, 438(7066), 310.

[7] Kolokotroni, M., Giannitsaris, I., \& Watkins, R. (2006). The effect of the London urban heat island on building summer cooling demand and night ventilation strategies. Solar Energy, 80(4), 383-392.

[8] Sarrat, C., Lemonsu, A., Masson, V., \& Guedalia, D. (2006). Impact of urban heat island on regional atmospheric pollution. Atmospheric Environment, 40(10), 1743-1758. 
Nevşehir Bilim ve Teknoloji Dergisi (2019), 8(Enar Özel Sayı) 64-78

[9] Grimmond, S. (2007). Urbanization and global environmental change: local effects of urban warming. Geographical Journal, 173(1), 83-88.

[10] Tan, J., Zheng, Y., Tang, X., Guo, C., Li, L., Song, G., ... \& Chen, H. (2010). The urban heat island and its impact on heat waves and human health in Shanghai. International Journal of Biometeorology, 54(1), 75-84.

[11] Oliveira, S., Andrade, H., \& Vaz, T. (2011). The cooling effect of green spaces as a contribution to the mitigation of urban heat: A case study in Lisbon. Building and Environment, 46(11), 2186-2194.

[12] Chen, K., Zhou, L., Chen, X., Ma, Z., Liu, Y., Huang, L., ... \& Kinney, P. L. (2016). Urbanization level and vulnerability to heat-related mortality in Jiangsu Province, China. Environmental Health Perspectives, 124(12), 1863-1869.

[13] Jonsson, P. (2004). Vegetation as an urban climate control in the subtropical city of Gaborone, Botswana. International Journal of Climatology, 24(10), 1307-1322.

[14] Potchter, O., Cohen, P., \& Bitan, A. (2006). Climatic behavior of various urban parks during hot and humid summer in the Mediterranean city of Tel Aviv, Israel. International Journal of Climatology, 26(12), 1695-1711.

[15] Yu, C., \& Hien, W. N. (2006). Thermal benefits of city parks. Energy and Buildings, 38(2), 105-120.

[16] Lafortezza, R., Carrus, G., Sanesi, G., \& Davies, C. (2009). Benefits and well-being perceived by people visiting green spaces in periods of heat stress. Urban Forestry \& Urban Greening, 8(2), 97-108.

[17] Zoulia, I., Santamouris, M., \& Dimoudi, A. (2009). Monitoring the effect of urban green areas on the heat island in Athens. Environmental Monitoring and Assessment, 156(1-4), 275.

[18] Georgi, J. N., \& Dimitriou, D. (2010). The contribution of urban green spaces to the improvement of environment in cities: Case study of Chania, Greece. Building and Environment, 45(6), 1401-1414.

[19] Yılmaz, H., Irmak, M.A., 2012. Yerleşke Planlamasında Bitkisel Tasarım İlkeleri; Atatürk Üniversitesi Yerleşkesi Örneği. Atatürk Üniversitesi Yayınları, 192, Erzurum.

[20] Breuste, J., Haase, D., \& Elmqvist, T. (2013). Urban landscapes and ecosystem services. Ecosystem Services in Agricultural and Urban Landscapes, 83-104.

[21] McPherson, E. G., \& Simpson, J. R. (2003). Potential energy savings in buildings by an urban tree planting programme in California. Urban Forestry \& Urban Greening, 2(2), 73-86.

[22] Wang, Z. (2006). A field study of the thermal comfort in residential buildings in Harbin. Building and Environment, 41(8), 1034-1039.

[23] Nowak, D.J., Crane, D.E \& Stevens, J.C., 2006. Air pollution removal by urban trees and shrubs in the United States. Urban Forestry and Urban Greening, 4;115-123.

[24] Öztürk, S. (2013). Kentsel açık ve yeşil alanların yaşam kalitesine etkisi "Kastamonu Örneği”" Kastamonu Üniversitesi Orman Fakültesi Dergisi, 13(1), 109-116.

[25] Bolund, P., \& Hunhammar, S. (1999). Ecosystem services in urban areas. Ecological economics, 29(2), 293-301.

[26] Nilsson, M. E., \& Berglund, B. (2006). Soundscape quality in suburban green areas and city parks. Acta Acustica united with Acustica, 92(6), 903-911.

[27] Özer, S., Irmak, M.A., Yılmaz, H., (2008). Determination of roadside noise reduction effectiveness of Pinus slyvestris L. and Populus nigra L. İn Erzurum, Turkey. Environmental Monitoring and Assessment, 144(1-3), 191-197. 
Nevşehir Bilim ve Teknoloji Dergisi (2019), 8(Enar Özel Sayı) 64-78

[28] Verheij, R. A., Maas, J., \& Groenewegen, P. P. (2008). Urban-rural health differences and the availability of green space. European Urban and Regional Studies, 15(4), 307-316.

[29] Dhingra, S. S., Strine, T. W., Holt, J. B., Berry, J. T., \& Mokdad, A. H. (2009). Rural-urban variations in psychological distress: findings from the Behavioral Risk Factor Surveillance System, 2007. International Journal of Public Health, 54(1), 16-22.

[30] Lambert, K. G., Nelson, R. J., Jovanovic, T., \& Cerdá, M. (2015). Brains in the city: neurobiological effects of urbanization. Neuroscience \& Biobehavioral Reviews, 58, 107-122.

[31] Beckett, K. P., Freer-Smith, P. H., \& Taylor, G. (1998). Urban woodlands: their role in reducing the effects of particulate pollution. Environmental Pollution, 99(3), 347-360.

[32] Upmanis, H., Eliasson, I., \& Andersson-Sköld, Y. (2001). Case studies of the spatial variation of benzene and toluene concentrations in parks and adjacent built-up areas. Water, Air and Soil Pollution, 129(1-4), 6181.

[33] Dimoudi, A., \& Nikolopoulou, M. (2003). Vegetation in the urban environment: microclimatic analysis and benefits. Energy and buildings, 35(1), 69-76.

[34] Fang, C. F., \& Ling, D. L. (2005). Guidance for noise reduction provided by tree belts. Landscape and Urban Planning, 71(1), 29-34.

[35] Nielsen, T. S., \& Hansen, K. B. (2007). Do green areas affect health? Results from a Danish survey on the use of green areas and health indicators. Health \& Place, 13(4), 839-850.

[36] Bratman, G. N., Hamilton, J. P., \& Daily, G. C. (2012). The impacts of nature experience on human cognitive function and mental health. Annals of the New York Academy of Sciences, 1249(1), 118-136.

[37] Hartig, T., Mitchell, R., De Vries, S., \& Frumkin, H. (2014). Nature and health. Annual Review of Public Health, 35, 207-228.

[38] Mennis, J., Mason, M., \& Ambrus, A. (2018). Urban greenspace is associated with reduced psychological stress among adolescents: A Geographic Ecological Momentary Assessment (GEMA) analysis of activity space. Landscape and Urban Planning, 174, 1-9.

[39] Kuo, F. E., Sullivan, W. C., Coley, R. L., \& Brunson, L. (1998). Fertile ground for community: Inner-city neighborhood common spaces. American Journal of Community Psychology, 26(6), 823-851.

[40] Maas, J., Van Dillen, S. M., Verheij, R. A., \& Groenewegen, P. P. (2009). Social contacts as a possible mechanism behind the relation between green space and health. Health \& Place, 15(2), 586-595.

[41] Fan, Y., Das, K. V., \& Chen, Q. (2011). Neighborhood green, social support, physical activity, and stress: Assessing the cumulative impact. Health \& Place, 17(6), 1202-1211.

[42] Home, R., Hunziker, M., \& Bauer, N. (2012). Psychosocial outcomes as motivations for visiting nearby urban green spaces. Leisure Sciences, 34(4), 350-365.

[43] De Vries, S., Van Dillen, S. M., Groenewegen, P. P., \& Spreeuwenberg, P. (2013). Streetscape greenery and health: stress, social cohesion and physical activity as mediators. Social Science \& Medicine, 94, 26-33.

[44] Sullivan, W. C., Frumkin, H., Jackson, R. J., \& Chang, C. Y. (2014). Gaia meets Asclepius: Creating healthy places. Landscape and Urban Planning, 127, 182-1

[45] Anonymous, 2019a. https://www.edenproject.com, Accepted Date: 12.02 .2019

[46] Anonymous, 2019b. https://www.gonomad.com/89333-the-eden-project-cornwall-england Accepted Date: 28.02.2019 
Nevşehir Bilim ve Teknoloji Dergisi (2019), 8(Enar Özel Sayı) 64-78

[47] Anonymous, 2019c. https://www.beesker.com/edenproject Accepted Date: 28.02.2019

[48] Anonymous, 2019d. https://tr.wikipedia.org, Accepted Date: 12.02.2019

[49] Anonymous, 2018a. http://www.orangesmile.com/extreme/tr/suslu-su-parklari/tropical-islands-resort, Accepted Date: 20.12.2018

[50] Anonymous, 2019e. https://www.tropical-islands.de, Accepted Date: 12.02.2019

[51] Anonymous, 2018b. https://www.sabah.com.tr/galeri/dunya/almanyanin-en-buyuk-tropik-adasi/2, Accepted Date: 20.12.2018

[52] Anonymous, 2018c. https://www.ntv.com.tr/galeri/yasam/almanyanin-tropik-adalari, Accepted Date: 20.12.2018

[53] Anonymous, 2018d. http://www.orangesmile.com/extreme/tr/suslu-su-parklari/seagaia-okyanus-kubbesi, Accepted Date: 21.12.2018

[54] Anonymous, 2018e. https://www.amusingplanet.com/2012/01/seagaia-ocean-dome-artificial-beachin.html, Accepted Date: 21.12.2018

[55] Anonymous, 2018f. http://www.forumgercek.com/109249-post1.html, Accepted Date: 21.12.2018

[56] Anonymous, 2018g. http://www.orangesmile.com/extreme/tr/suslu-su-parklari/water-cube, Accepted Date: 21.12 .2018

[57] Anonymous, 2018h. http://www.parcplaza.net/2010/08/pekin-inaugure-le-parc-aquatique-water.html, Accepted Date: 21.12.2018

[58] Anonymous, 2018i. https://tr.pinterest.com, Accepted Date: 22.12.2018

\section{Extended Abstract}

Erzurum kenti özellikle yüksek rakımla beraber ortaya çıkan ekstrem iklim şartları nedeni ile diğer kentlerimizden ayrıcalık göstermektedir. Bundan dolayı dış mekanlarda gerek yapısal gerekse bitkisel tasarım ve uygulamalarda klasik anlayışın dışında yeni yaklaşımlara ihtiyaç duyulmaktadır. Kentteki mevcut açık-yeşil alanların bütün yıl boyu kullanıma yönelik aktiviteleri yeterli değildir. İnsanlar uzun ve sert geçen kış aylarında kış turizminden yararlanamayan kent insanı dış mekan peyzaj alanlarını kullanamamakta ve zamanının çoğunu kapalı alanlarda geçirmektedir. Kent insanı kış aylarında rekreasyonel taleplerini daha çok kapalı alanlara sahip olan az sayıdaki alış veriş merkezlerinde zorunlu olarak geçirmeye çalışmaktadır. Bundan dolayı Erzurum gibi ekstrem iklim şartlarına sahip kentlerimizde yıl boyu peyzaj mekanları oluşturulması önemlidir. $\mathrm{Bu}$ çalışmada bölgemize ve ülkemize bir model oluşturulması hedeflenen Erzurum için yeni bir konsept olarak ilk kez kapalı peyzaj/Peyzaj 12 kavramı gündeme getirilmesi hedeflenmiştir.

\section{Giriş}

Son on yılda, dünya genelinde özellikle gelişmekte olan ülkelerde kentsel alanlarda insan yoğunluğu artış göstermektedir [1]. Dünya nüfusunun yarısından fazlası kentsel alanlarda yaşamaktadır ve bu değerin 2050 yılına kadar \%66 'ya yükselmesi beklenmektedir [2;3]. Kentleşme süreci ile birlikte; kentsel alanların genişlemesi, genellikle yerel iklimdeki değişiklikler, çevresel koşulların bozulması, kentsel 1sı adası (UHI) etkisinin artması, hava ve gürültü kirliliği seviyelerinin artması, soğutma enerjisi tüketiminin artması, yaşam kalitesinin düşmesi, kentsel sürdürülebilirlik ilkelerinin ihlali gibi bir çok sorun meydana gelmektedir [4-5-6-7-8-9-10-11-12].

$\mathrm{Bu}$ çalışmada bir maden ocağının ıslah edilerek özgün bir yapısına dönüştürülen "Eden Project", bir uçak hangarının dönüştürülmesi ile ortaya çıkan "Tropical Islands Resort", tamamen kapalı peyzaj anlayışı ile oluşturulan "Seagaia Ocean Dome" ve olimpiyatlar için inşa edilip su parkına dönüştürülen "Happy Magic Water Cube" uygulamaları üzerinde durulmuştur. Bu örnekler değerlendirilerek, bölgemize ve ülkemize bir model oluşturması hedeflenen Erzurum için yeni bir konsept olarak kapalı peyzaj kavramı üzerinde durulmuştur 


\section{Metod}

İnsanların rekreasyonel taleplerinin karşılanmasına yönelik öncelikle dünyadaki az sayıda örnekleri bulunan kapalı peyzaj alanları değerlendirilmiştir. Bu amaçla 4 kapalı peyzaj kompleksi görsel materyalle tanıtımı yapılmıştır. Daha sonra Erzurum kentinin mevcut durumu analiz edilerek, Peyzaj 12 Mimari tasarım projesi oluşturulmuştur. Proje kapsamında yıl boyu peyzaj yaklaşımının kente sağlayacağı yararlar analiz edilmeye çalışılmıştır.

\section{Tartışma ve Sonuç}

Yurtdışı kapalı peyzaj uygulamaları üzerinde bilgiler ortaya konmuştur. Erzurum kentinin doğal ve sosyo-kültürel ve ekonomik yapısı dikkate alınarak açık-yeşil alan tasarımlarına yeni bir yaklaşım geliştirilmiştir. Bu yaklaşımının temelinde yıl boyu dış mekan açık-yeşil alanlarının kent insanına hizmet verecek donatılara sahip olması oluşturmaktadır. Daha önce yapılan değişik bilimsel araştırmalarda Erzurum kent insanının kış aylarında daha çok zorunlu olarak alış veriş merkezlerini tercih ettikleri sonucundan yola çıkarak Yıl Boyu Peyzaj/ Peyzaj 12 kavramı geliştirilmiştir.

Mevcut bir çocuk oyun alanı proje alanı olarak seçilmiş, çevre analizleri yapılarak, mimari bir model oluşturulmuştur. Mimari tasarımında doğadan esinlenmiş, biyo-mimikri tasarımı geliştirilmiştir. Enerjiyi etkin kullanan akıllı bina konseptine uygun olarak tasarlanan binanın görsellerine yer verilmiştir. Bu yapı içinde; açık-yeşil alanlar, buz müzesi, mini arboretum (bitki müzesi), yöresel el sanatları müzesi, gastronomi vb. ünitelere yer verilebileceği üzerinde durulmuştur. Binanın uygulanması aşamaları bir tasarım ve uygulama sürecinde ele alınmıştır.

Projenin ekonomik, ekolojik, estetik, psikolojik ve prestij yönünden yararları üzerinde durulmuştur. Aynı zamanda bu kompleksin getireceği ekonomik maliyet ve diğer olumsuzluklar da analiz edilmeye çalışılmıştır. Yerel aktörlerin projeye dahil edilmesi konusunda bir taslak oluşturulmuştur. Kent insanına tüm yıl boyu rekreasyonel firsatlar sunması yanısıra, kenttin marka değerini artıracağı sonucuna varılmıştır. Bütün kış ayları boyunca kullanılamayan dış mekan açık-yeşil alanlara yapılan yatırımların yeni bir anlayışla kapalı peyzaj mekanlarına yer verilerek ele alınması gerekliliği ortay çıkmıştır. Ayrıca bölgedeki diğer kentler için de bir model olması üzerinde durulmuştur.

Ekstrem iklim şartlarına sahip olan Erzurum gibi soğuk kent kimliği taşıyan kentsel mekanlarda dış mekan peyzaj düzenlemelerinde yeni yaklaşımlara ihtiyaç vardır. Bu çalışmada ilk kez yıl boyu peyzaj/Peyzaj 12 kavramı gündeme gelmiştir. Kaynakların etkin kullanılması amacı ile tüm kent parklarımızın bu konsepte ele alınması gerektiği sonucuna varılmıştır. Dış mekan kullanımını bütün yıla yayma açısından kapalı peyzaj mekan düzenlemeleri maliyeti yüksek olmakla beraber, iyi bir kış dostu peyzaj kullanımı olarak yararlı görülmektedir. Bu mekanlar aynı zamanda kentlerin marka değerlerini artırmada etkin rol üstlenebilirler. Sadece kent halkının rekreasyonel taleplerini karşılamakla kalmayıp, aynı zamanda kentin turizminin de çeşitlendirilmesine katkı sağlaması beklenmektedir. 